\title{
Pengaruh Strategi Coping Stress Terhadap Stres Akademik Mahasiswa yang Mengerjakan Skripsi di Jurasan Pendidikan MIPA IAIN Kendari
}

\author{
Nursoleha Tri Oktafiani ${ }^{1)}$; Aliwar ${ }^{2)}$ \\ 1) Alumni Tadris Biologi, Fakultas Tarbiyah dan Ilmu Keguruan (FTIK), Institut Agama Islam Negeri (IAIN) \\ Kendari; \\ 2) Dosen FTIK, IAIN Kendari
}

\begin{abstract}
The purpose of this article is to find out: 1) Description of stress coping strategies, 2) Description of student academic stress, 3) The effect of stress coping strategies on academic stress of students working on thesis at the MIPA Education Department, IAIN Kendari. This type of research is a quantitative research using a survey method using a letter (mail-questionare). The survey method is an investigation carried out to obtain facts from existing symptoms to seek factual information either with social, political or economic intuition from a group or individual. The research location is in the Mathematics and Natural Sciences Education Department, IAIN Kendari, with the research samples being Biology, Natural Sciences, Mathematics and Physics. The results showed that: 1) the stress coping strategy had an average value of $52.1 \%$ of students in the medium category. the highest indicator is found in the positive reaprasial indicator of $56.3 \%$ of students using this strategy in dealing with stress, 2) academic stress has an average value of $52.1 \%$ in the medium category, the indicator with the highest categorization is found in the cognitive apprasial indicator of 52, 1\% of students in assessing situations that can cause stress perform cognitive assessments. 3) stress coping strategies have a positive and significant effect on academic stress, with a value of Fcount $=25.04>$ Ftable $=3.98$ and or a significance value of $0.00<0.05$ with a contribution to the assessment of coping stress on academic stress of $26.6 \%$.
\end{abstract}

Keywords: Coping stress, academic stress, thesis

\begin{abstract}
Abstrak
Tujuan penelitian artikel ini untuk mengetahui: 1) Deskripsi strategi coping stress, 2) Deskripsi stres akademik mahasiswa, 3) Pengaruh strategi coping stress terhadap stres akademik mahasiswa yang mengerjakan skripsi di Jurusan Pendidikan MIPA IAIN Kendari. Jenis penelitian ini adalah penelitian kuantitatif menggunakan metode survey dengan menggunakan surat (mail-questionare). Metode survey adalah penyelidikan yang dilakukan untuk mendapatkan fakta-fakta dari gejala yang ada untuk mencari keterangan secara faktual baik dengan intuisi sosial, politik atau ekonomi dari suatu kelompok atau individu. Lokasi penelitian di Jurusan Pendidikan MIPA IAIN Kendari dengan sampel penelitian yaitu program studi tadris Biologi, Tadris IPA, Tadris Matematika dan Tadris Fisika. Hasil Penelitian menunjukan bahwa : 1) strategi coping stress memiliki nilai rata-rata sebesar $52,1 \%$ mahasiswa dengan kategori sedang. indikator tertinggi terdapat pada indikator positive reaprasial sebesar 56,3\% mahasiswa menggunakan strategi tersebut dalam menghadapi stres, 2) stres akademik memiliki nilai rata-rata sebesar 52,1\% dengan kategori sedang, indikator dengan kategorisasi tertinggi terdapat dalam indikator cognitive apprasial sebesar 52,1\% mahasiswa dalam menilai situasi yang dapat menyebabkan stres melakukan penilaian kognitif. 3) strategi coping stress berpengaruh positif dan signifikan terhadap stres akademik, dengan nilai $\mathrm{F}_{\text {hitung }}=25,04>\mathrm{F}_{\text {tabel }}=3,98$ dan atau nilai signifikansi sebesar $0,00<0,05$ dengan sumbangan penilaian coping stress pada stres akademik sebesar $26,6 \%$.
\end{abstract}

Kata Kunci: Coping stress, stres akademik, skripsi

\section{PENDAHULUAN}

Pendidikan merupakan upaya meningkatkan kualitas Sumber Daya Manusia (SDM) (Amalia et al. (2020). Peningkatan SDM salah satunya dengan menempuh perkuliahan. Tahap akhir dari perkuliahan adalah penyelesaian tugas akhir atau skripsi. Skripsi merupakan laporan riset karya ilmiah yang tulisdari hasil penelitian lapangan atau kepustakaan dan dipertahankan di depan ujian munaqasyah dalam penyelesaian studi tingkat Strata Satu (S1) untuk memperoleh gelar sarjana (Fua \& Gunawan, 2014).

Tekanan dalam perkuliahan bagi mahasiswa adalah penulisan tugas akhir atau skripsi. Tuntutan yang diperoleh dari berbagai pihak, baik dari pihak akademik maupun non akademik. Mahasiswamenuntut ilmu di perguruan tinggi dalam kegiatannya tidak terlepas dari stres. Stres adalah bagian dari faktor yang mempengaruhi proses dalam pendidikan dan kesejahteraan siswa/mahasiswa (Kumar, 2011). Menurut Jayasankara Reddy et al. (2018), stres memiliki tiga topik terkait perubahan rangsangan dari lingkungan yang menyebabkan stres (disebut stresor), respon psikologis dan fisiologis (respon stres) dan penyakit yang dihasilkan dari stimulasi berlebihan 
terhadap respons fisiologis dan psikologis (efek stres kronis). Secara biologis menurut Ulrich-Lai \& Herman (2009), kelangsungan hidup dan kesejahteraan semua spesies membutuhkan respons fisiologis yang sesuai tantangan lingkungan dan homeostatis. Lingkungan yang ada saat ini suatu saat nanti akan mengalami penurunan kualitas (Yulita \& Susiono, 2020). Pembentukan kembali dan pemeliharaan homeostasis terhadap lingkungan memerlukan aktivasi dan kontrol koordinat sistem stres neuroendokrin dan otonom.

Stres akademik merupakan hal normal yang terjadi karena proses perkembangan diri seperti menyesuaikan diri, mendapatkan peran dan tanggungjawab dan menghadapi konsep-konseppendidikan yang berbeda dengan masa sekolah sebelumnya, ketidakmampuan manajeman waktu, harapan dan tantangan terhadap pencapaian akademik, perubahan gaya hidup dan perkembangan konsep diri (Regehr et al., 2013).

Stres yang dialami mahasiswa ketika mengerjakan skripsi diperkuat oleh Wijayanti (2013) dalam penelitiannya secara umum mahasiswa FKIP angkatan 2008 mengalami stres dalam penyusunan skripsi pada kategori sedang sebesar 77,9\%. Strategi coping stress yang dialami mahasiswa dengan meluapkan emosi dari dua sisi, baik emosi positif maupun negatif. Penelitian oleh Kumar, (2011), melakukan strategi coping stress dengan menggunakan strategi problem focused coping dan emotional focused coping.

Penelitian oleh Indra Rukamana (2019), pengaruh coping stress dan dukungan sosial terhadap stres akademik mahasiswa berperngaruh 16,6\%, dengan tiga variabel yang menunjukan terdapat pengaruh yang signifikan dengan mengelola stres akademik yaitu maladaptive coping, reassurance of worth dan reliable alliance.

Diketahui data awal kuisioner mahasiswa yang mengerjakan skripsi menimbulkan respon fisiologis dan psikologis seperti mengalami gejala cemas, sedih, sakit kepala, tidur tidak teratur, diare, cepat marah, khawatir, gelisah, kecenderungan menyendiri, melamun, menghindari bertemu orang-orang tertentu, penurunan atau peningkatan massa tubuh yang drastis. Hal tersebut dipengaruhi oleh ketidakmampuan mahasiswa dalam mengelola emosional dan memfokuskan diri dalam menyelesaikan masalah. Mahasiswa dapat mengotrol stres dengan baik apabila dapat memfokuskan diri dalam menyelesaikan masalah, memanajemen emosi dengan mencari dukungan informasi atau informasi pendukung, menyelesaikan masalah secara kongkret dan melakukan perencanaan pemecahan masalah. Hal tersebut dapat menjadi asusmsi bahwa terdapat kaitan antara strategi mengelola stres dengan stres akademik mahasiswa yang mengerjakan skripsi.

Berdasarkan hal tersebut peneliti berfokus untuk menentukan pengaruh strategi yang digunakan terhadap stres akademik yang dialami mahasiswa dengan menentukan dominansi dimensi dan indikator pada variabel terikat dan variabel bebas tersebut. Strategi yang digunakan dengan coping stress dengan indikator penilaian menggunakan seeking informational support, confrontative coping, planful problem solving, dalam bentuk penilaian fokus pemecahan masalah. Sedangkan penilaian berfokus pada emosional dengan menggunakan indikator seeking social emotional, distancing, excape avoidance, self control, accepting responsibility dan positive reaprasial. Menentukan dominansi stres akademik dengan pengkategorisasian menggunakan dimensi stresor akademik dan reaksi terhadap stresor. Kategorisasi dimensi stresor akademik dengan menggunakan indikator frustation, conflics, preassures, changes, self-imposed. Sedangkan pada dimensi reaksi terhadap stresor dengan menggunkan indikator physiological, emotional dan cognitive apprasial.

\section{METODOLOGI PENELITIAN}

Penelitian ini menggunakan pendekatan kuantitatif, dengan menggunakan metode survei. Populasi dalam penelitian ini adalah seluruh mahasiswa Jurusan Pendidikan MIPA yang sedang mengerjakan skripsi di IAIN Kendari yang berjumlah 71 mahasiswa. Teknik pengambilan sampel dilakukan dengan mengambil $100 \%$ dari jumlah populasi, hal tersebut dilakukan berdasarkan kutipan dri Arikunto (2014) apabila jumlah populasi kurang dari 100 orang, maka jumlah sampelnya diambil secara keseluruhan atau 100\%.Teknik pengumpulan data menggunakan kuesioner, dokumentasi, dan instrumen tes yang telah diuji validitas dan reliabilitasnya. Kuisioner yang digunakan dalam penelitian ini sebagai berikut.

Tabel 1. Kuisioner Coping Stress

\begin{tabular}{|c|c|c|}
\hline Variabel & Dimensi & Indikator \\
\hline Jenis $\quad$ Strategi & Problem & Seeking informational support (Mencari dukungan informasi) \\
\hline \multirow[t]{7}{*}{ Coping } & Focused & Confrontative coping (menyelesaikan masalah secara kongkrit) \\
\hline & Coping & Planful Problem Solving (perencanaan pemecahan masalah) \\
\hline & $\begin{array}{l}\text { Emotional } \\
\text { Focused }\end{array}$ & Seeking social emotional (memperoleh dukungan secara emosional) \\
\hline & Coping & Distancing (upaya kognitif atau membuat harapan positif) \\
\hline & & Excape avoidance (berandai-andai atau penghindaran masalah) \\
\hline & & Self control (pengendalian emosi atau mengatur perasaan) \\
\hline & & Accepting responsibility (menerima tanggungjawab) \\
\hline
\end{tabular}


Tabel 2. Kuisioner Stres Akademik

\begin{tabular}{lll}
\hline \multicolumn{1}{c}{ Variabel } & Dimensi & \multicolumn{1}{c}{ Indikator } \\
\hline Dimensi Stres & Stressor & Hambatan yang berasal dari dalam diri \\
Akademik & akademik & Hambatan yang berasal dari lingkungan keluarga \\
& & Hambatan dari lingkungan \\
& & Keterlambatan dalam mencapai tujuan \\
& Kesulitan sehari-hari \\
& Konflik antara dua pilihan \\
& Konflik yang terjadi dengan orang tua \\
& Konflkik dengan diri sendiri \\
& Konflik yang terjadi dengan teman \\
& Harapan dari keluarga atau orang lain \\
& Beban kuliah \\
& Tekanan atau tuntutan dari keluarga \\
& Tekanan atau tuntutan dari keluarga \\
& Perubahan hidup yang mengganggu \\
& Situasi atau kondisi yang dapat merugikan diri sendiri \\
& Kecemasan \\
& Gangguan biologis \\
& Reaksi & Perasaan tidak menyenangkan \\
& stressor & Menyakiti diri sendari dan orang lain \\
& Penilaian masalah \\
&
\end{tabular}

Teknik analisis data yang digunakan adalah analisis statistik deskriptif dan analisis statistik inferensial. Analisis statistika deskriptif, yaitu menghitung rata-rata, rentang data, jumlah kelas intrval, panjang kelas, variansi, standar deviasi, persentase dan kategori. Sedangkan analisis statistika inferensial diawali dengan melakukan uji persyaratan analisis, yaitu; uji normalitas, uji linearitas, uji multikolinieritas, uji autokorelasi, dan uji heteroskedasitas.

\section{HASIL DAN PEMBAHASAN}

\section{HASIL}

Data hasil penelitian pengaruh strategi coping stress terhadap stres akademik mahasiswa yang sedang mengerjakan skripsi, yang diukur dengan menggunakan kuisioner, dokumetasi, kemudian diolah dan di analisis secara deskriptif dalam tabel berikut:

Tabel1.DistribusiKategorisasi Strategi Coping Stress

\begin{tabular}{cccc}
\hline Kelas interval & $\begin{array}{c}\text { Frekuensi } \\
(\mathbf{F})\end{array}$ & Presentase (\%) & Kategori \\
\hline $\mathrm{X}>150,04$ & 4 & 5,6 & Tinggi \\
$126,14<\mathrm{X}<150,04$ & 37 & 52,1 & Sedang \\
$102,24 \leq \mathrm{X}<150,04$ & 23 & 32,4 & Rendah \\
Dibawah 102,24 & 7 & 32,4 & Sangatrendah \\
Total & 71 & 100 & \\
\hline
\end{tabular}

Sumber: Data Primer Diolah, 2020 


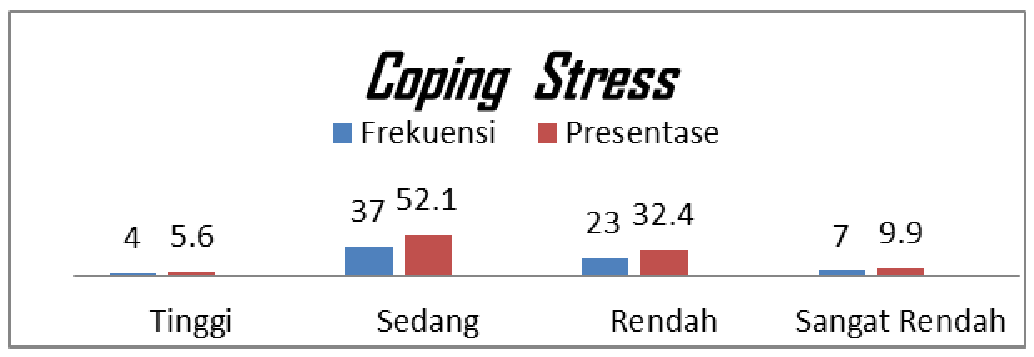

Dari gambar di atas menunjukkan mahasiswa jurusan pendidikan MIPA Fakultas Tarbiyah dan IlmuKeguruan IAIN Kendari dihitung dari jumlah sampel 71mahasiswa, mahasiswa yang memiliki kategori tinggi sebanyak 4 (5,6\%) mahasiswa, kategori sedang sebanyak 37(52,1\%) mahasiswa,kategori rendah sebanyak 23(32,4\%) mahasiswa, danyang memiliki kategori sangat rendah sebanyak 7(9,9\%) mahasiswa.

Tabel 2. DistribusiFrekuensi Stres Akademik

\begin{tabular}{cccc}
\hline Skor & Frekuensi & \% & Kategori \\
\hline$X \geq 118,08$ & 1 & 1,4 & Tinggi \\
$93,4 \leq X<118,08$ & 41 & 57,7 & Sedang \\
$68,8 \leq X<93,4$ & 27 & 38,02 & Rendah \\
Dibawah 68,8 & 2 & 2,8 & SangatRendah \\
Total & 59 & 100,00 & \\
\hline
\end{tabular}

Sumber: Data Primer Diolah, 2020

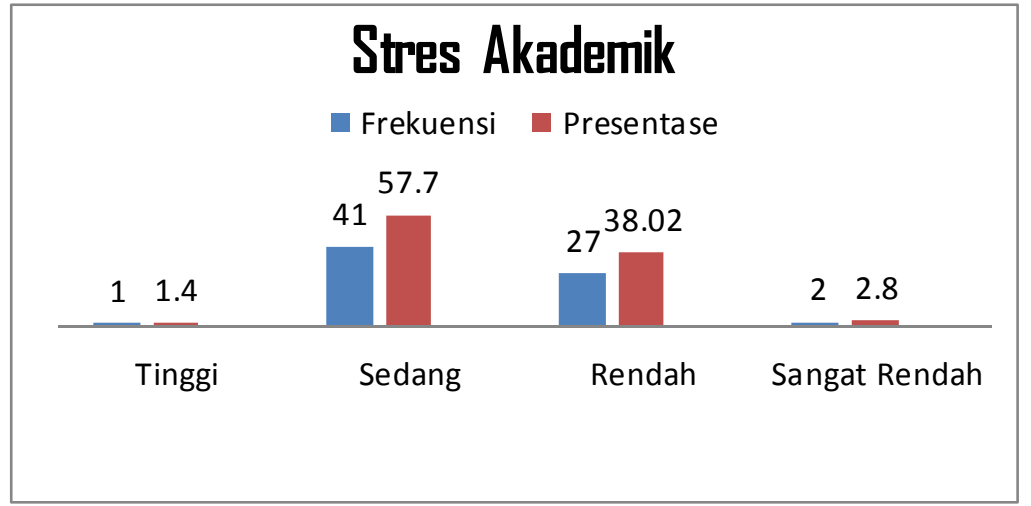

Gambar di atas, menunjukkanMahasiswa Fakultas Tarbiyah dan Ilmu Keguruan IAIN Kendari dihitung dari jumlah sampel 71 mahasiswa, mahasiswa yang memiliki kategori tinggi sebanyak $1(1,4)$ mahasiswa, kategori sedang sebanyak 41(57,7\%) mahasiswa, kategori rendah sebanyak 27(38,02)mahasiswa dan yang memiliki kategori sangat rendah sebanyak $2(2,8 \%)$ mahasiswa.

\section{Uji Persyaratan Analisis}

Sebelum pengujian hipotesis, terlebih dahulu dilakukan analisis inferensial, yaitu uji normalitas, dan uji linearitas.

\section{a. Uji Normalitas}

Tabel 3. Uji Normalitas Coping Stress dan Stres Akademik

\begin{tabular}{ccccc}
\hline Variabel & $\mathbf{D}_{\text {hitung }}$ & $\mathbf{D}_{\text {table }}$ & $\alpha$ & Ket \\
\hline Coping Stress $(\mathrm{X})$ & 0,137 & 0,161 & 0,05 & Normal \\
Stres Akademik (Y) & 0,106 & 0,161 & 0,05 & Normal \\
\hline
\end{tabular}

Sumber: Data Primer Diolah, 2020

Hasil perhitungan yang diperoleh, nilai Dhitung $>$ Dtabel (taraf signifikansi $\alpha=0,05$ ), menunjukkan bahwa sebaran data untuk variabel coping stress, dan stres akademik adalah normal.

b. Uji Linearitas

Tabel 4.. Hasil Uji Linieritas

$\begin{array}{llll}\text { Variabel } & \text { F }_{\text {hitung }} & \text { F }_{\text {tabel }} & \text { Kesimpulan }\end{array}$




\begin{tabular}{|c|c|c|c|}
\hline Coping Stress (X) dan Stres & 0903 & 10623 & I inear \\
\hline
\end{tabular}

Sumber: Data Primer Diolah, 2020

Berdasarkan hasildi atas menunjukan nilai variabel coping stress (X) dan stres akademik (Y) mempunyai hubungan yang linear.

Uji hipotesis

Berdasarkan deskripsi data dan uji prasyarat analisis, telah menunjukan data berdistribusi normal dan linear, maka pengajuan hipotesis dapat dilaksanakan.

Tabel 5. Hasil Uji Regresi Linear Sederhana

\begin{tabular}{lccc}
\hline \multicolumn{1}{c}{ Variabel } & Hasil & Sig. & Ket \\
\hline Konstanta & 41,826 & 0,000 & Sig \\
$X$ & 0,409 & 0,000 & Sig \\
\hline
\end{tabular}

Sumber: Data Primer Diolah, 2020

Berdasarkan hasil tabel di atas dapat dijelaskan arah pengaruh variabel $\mathrm{X}$ terhadap $\mathrm{Y}$ adalah positif, dengan persamaan yang dapat dituliskan yaitu: $\mathrm{Y}=41,826+0,409$.

Tabel 5. Uji Signifikansi (Keberartian Koefisien Regresi)

\begin{tabular}{cc}
\hline F & Sig. \\
\hline 25,04 & 0,000 \\
\hline
\end{tabular}

Sumber: Data Primer Diolah, 2020

Berdasarkan tabel di atas, menunjukan semua variabel independen X (Coping Stress) berpengaruh signifikan terhadap variabel dependen Y (Stres Akademik).

Tabel 6. Uji Korelasi Person Product Moment

\begin{tabular}{ccccc}
\hline Variabel & Pearson Correlations & Sig. & N & Ket \\
\hline Coping Stress $\left(\mathbf{X}_{1}\right)$ & 0,516 & 0,000 & 71 & \multirow{2}{*}{ Berkorelasi } \\
Stress Akademik $(\mathrm{Y})$ & 0,516 & 0,000 & 71 & \\
\hline
\end{tabular}

Sumber: Data Primer Diolah, 2020

Berdasarkan tabel di atas dapat dikatakan bahwa (semakin tinggi variabel X (coping stress) semakin tinggi pula variabel Y (stres akademik).

Tabel 7. Uji t (Uji Parsial)

\begin{tabular}{ccc}
\hline thitung & Sig. & t tabel \\
\hline 5,004 & 0,000 & 1,995 \\
\hline Sumber: Data Primer Diolah, 2020 &
\end{tabular}

Berdasarkan tabel di atas, menunjukan bahwa variabel coping stress $(\mathrm{X})$ berpengaruh terhadap variabel stres akademik (Y).

Tabel 8. Hasil Uji Koefisien Determinasi

\begin{tabular}{ccc}
\hline Variabel Terikat & ${\text { Nilai } \mathbf{~ r}^{2}}$ & Persentase \\
\hline Coping Stres $(\mathrm{X})$ & 0,2662 & $26,62 \%$ \\
\hline Sumber: Data Primer Diolah, 2020 &
\end{tabular}

Berdasarkan tabal di atas menunjukan besarnya pengaruh strategi coping stress terhadap stres akademik mahasiswa yang mengerjakan skripsi di Fakultas Tarbiyah dan Ilmu Keguruan IAIN Kendari sebesar 26,62\%.

\section{PEMBAHASAN}

Deskripsi Strategi Coping Stress di Jurusan Pendidikan MIPA

Setelah dilakukan hasil penelitian untuk mengetahui coping stress, dilakukan penentuan kategorisasi coping stress. Penentuan kategorisasi yang telah dilakukan maka di dapatkan hasil bahwa pada coping stress yang memiliki kategori tinggi sebanyak 4 (5,6\%) mahasiswa, kategori sedang sebanyak $37(52,1 \%)$, kategori rendah sebanyak 23 (32,3\%), dan kategori sangat rendah sebanyak 7 (9,9\%) mahasiswa. 
Berdasarkan hasil data yang diperoleh maka dapat dijelaskan bahwa variabel tertinggi strategi coping stress berkategori sedang sebanyak 37 (52,1\%) mahasiswa. Hasil dari variabel strategi coping stress lebih spesifik dengan kategorisasi mahasiswa yang memiliki kategori tertinggi dari aspek-aspek indikator lain terdapat pada dimensi emotional focused coping, indikator positive reaprasial sebanyak 40 mahasiswa atau 56,3\% dengan rata-rata 22,4 berada padakategori sedang. Positive reaprasial, yaitu mencoba membuat suatu arti positif dari situasi yang dihadapi, hal ini dapat berupa religiusitas, meditasi dan menghadapi masalah dengan menjalani dan berpikir positif. Ketika mahasiswa cenderung mengatasi stres dengan melakukan hal seperti mencari dukungan emosional dengan pendekatan spiritual untuk menumbuhkan pemikiran positif, mengatur emosi stres dan melihat masalah dari sudut pandang yang lebih positif, dan mencari dukungan moral, simpati, serta pemahaman dari orang lain, ataupun dengan cara menyangkal. Hal tersebut dapat terjadi karena mahasiswa yang menggunakan emotion focused coping, akan cenderung berfokus untuk mengatasi gejolak emosi atau tekanan yang dirasakannya, yang secara tidak langsung dapat menghambat proses pemecahan masalah yang berdampak pula pada proses akademik mahasiswa. Hasil ini diperkuat oleh penelitian Sipayung (2016), mahasiswa yang mengalami stres memiliki kemampuan coping stress yang cukup baik. Coping stress yang cukup baik atau dalam kategori sedang artinya mahasiswa mampu dalam memanajemenkan tindakan dengan memecahkan masalah yang sederhana dan realistis Lazarus dalam (Basler, 1996).

\section{Deskripsi Stres Akademik Mahasiswa di Jurusan Pendidikan MIPA}

Setalah dilakukan penentuan kategorisasi stres akademik guna untuk mengetahui berapa banyak mahasiswa yang berada pada kategori tinggi, sedang, rendah dan sangat rendah. Berdasarkan penentuan kategorisasi yang telah dilakukan maka diperoleh hasil pada stres akademik yang memiliki kategori tinggi sebanyak $1(1,4 \%)$ mahasiswa,kategori sedang sebanyak 41(57,7\%), kategori rendah sebanyak 27 (38,02\%), dan kategori sangat rendah sebanyak 2(2,8\%) mahasiswa.

Berdasarkan hasil data yang diperoleh maka dapat dijelaskan bahwa variabel stres akademik berkategori sedang, dengan jumlah terbanyak dengan jumlah mahasiswa 41 (57,7\%). Hasil dari variabel stres akademik lebih spesifik dengan kategorisasi mahasiswa yang memiliki kategori tertinggi dari aspek-aspek indikator lain terdapat pada dimensi reaksi terhadap stresor, indikator cognitive apprasial (penilaian kognitif) sebanyak 37(52,1\%) mahasiswa, dengan rata-rata 3,3 berada padakategori tinggi. Menurut Stuart dan Sundeen (2005) pada tingkat stres sedang, manusia lebih memfokuskan hal-hal penting saat ini dan mengesampingkan yang lain sehingga mempersempit lahan persepsinya.

Berdasarkan hasil dari kedua variabel di atas yaitu strategi coping stress dan stres akademik, maka dijelaskan bahwa kecendrungan variabel strategi coping stress dan stres akademik berkategori sedang. Jadi hal ini dapat menunjukan mahasiswa mengurangi stres dalam mengerjakan skripsi dengan melakukan aktivitas lain seperti bertukar pikiran dengan orang yang lebih mampu, refreshing, membaca al-quran, beribadah lebih serius, berdoa atau tidur. Hal tersebut diperkuat oleh penelitian sebelumnya Pariat et al. (2014), stres akademik berpengaruh positif dengan strategi coping stress seperti tidur dan meditasi dalam mengurangi stres.

\section{Strategi Coping Stress Berpengaruh Terhadap Stres Akademik di Jurusan Pendidikan MIPA Fakultas Tarbiyah dan Ilmu Keguruan IAIN Kendari}

Berdasarkan hasil perhitungan uji regresi linear sederhana, untuk mengetahui arah pengaruh variabel bebas terhadap variabel terikat, dengan melihat nilai persamaannya. Koefisien regresi tersebut bernilai positif, sehingga arah pengaruh variabel $X$ terhadap $Y$ adalah positif, dengan persamaan $Y=41,826+0,409 X$.

Uji signifikansi menunjukan hasil analisis diperkuat dengan nilai $F_{\text {tabel }}$ sebesar 3,98. Nilai $F_{\text {hitung }}(25,04)>$ $\mathrm{F}_{\text {tabel }}(3,98)$ dan $0,000<0,05$ nilai signifikansi. Hasil uji $\mathrm{F}$ menunjukan variabel independen coping stress $(\mathrm{X})$ berpengaruh signifikan terhadap variabel stres akademik $(\mathrm{Y})$.

Uji determinasi menunjukan nilai koefisien determinasi $\left(\mathrm{R}^{2}\right)$ sebesar 0,516,sehingga besar sumbangan strategi coping stress terhadap stres akademik yaitu 26,62\% Jadi besar pengaruh strategi coping stress terhadao stres akademik di Jurusan Pendidikan MIPA IAIN Kendari yaitu sebesar 26,62\% sedangkan sisanya dipengaruhi oleh variabel yang tidak diteliti sbesar 73,38\%.

Berdasarkan penjelasan di atas diketahui bahwa terdapat pengaruh positif dan signifikan strategi coping stress terhadap stres akademik mahasiswa yang mengerjakan skripsi di Jurusan Pendidikan MIPA yaitu sebesar $26,62 \%$.

Hasil penelitian ini diperkuat oleh riset penelitian Rukmana (2019) menunjukan variabel strategi coping stress dan dukungan sosial yang digunakan berpengaruh sebesar 16,6\% dalam mengelola stres akademik, sedangkan sisanya $83,4 \%$ dipengaruhi oleh variabel lain di luar penelitian. Adapun perbedaan dan persamaan dari hasil reset dia dengan penelitian yang peneliti lakukan, yaitu persamaannya adalah penelitiannya menggunakan variabel strategi coping stress dan stres akademik, spesifik mahasiswa yang mengerjakan skripsi, adapun 
perbedaannya yaitu peneliti meneliti tentang pengaruh dengan tiga variabel, fokus hasil penelitian dan mahasiswa yang diteliti berbeda.

\section{KESIMPULAN}

Berdasarkan penelitian yang telah diuraikan sebelumnya maka dapat diambil kesimpulan sebagai berikut:

1) Strategi coping stress mahasiswa Jurusan Pendidikan MIPA, berdasarkan distribusi kategorisasi variabel coping stress rata-rata berkategori sedang yaitu sebanyak $37(52,1 \%)$ mahasiswa. Indikator dengan kategorisasi tertinggi dari aspek-aspek lain terdapat pada dimensi emotional focuse coping, dalam indikator positive reaprasial sebanyak $40(56,3 \%)$ mahasiswa menggunakan strategi ini dalam menghadapi stres.

2) Stres akademik berdasarkan distribusi kategorisasi bahwa kecendrungan variabel stres akademik mahasiswa Jurusan Pendidikan MIPA Fakultas Tarbiyah dan Ilmu Keguruan IAIN Kendari, rata-rata berada pada kategori sedang yaitu $41(57,7 \%)$ mahasiswa. Indikator dengan kategorisasi tertinggi dari aspek-aspek lain terdapat pada dimensi reaksi terhadap stresor, dalam indikator cognitive apprasial(penilaian kognitif) sebanyak $37(52,1 \%)$ mahasiswa.

3) Strategi coping stress berpengaruh positif dan signifikan terhadap stres akademik mahasiswa, dengan nilai $\mathrm{F}_{\text {hitung }}=25,04>\mathrm{F}_{\text {tabel }}=3,98$ dan atau nilai signifikansi sebesar $0,00<0,05$. Dengan sumbangan penilaian coping stress pada stres akademik sebesar $26,62 \%$ sisanya dipengaruhi oleh faktor lain yang tidak diteliti sebesar $73,4 \%$.

\section{DAFTAR PUSTAKA}

Amalia, H. A. M., Raoda, S., Sangila, M. S., Machmud, H., \& Samrin, S. (2020). Pengaruh Model Problem Based Learning Terhadap Hasil Belajar Siswa pada Materi Sistem Imun di SMA Negeri 6 Kendari. KULIDAWA, 1(1). https://doi.org/10.31332/kd.v1i1.1805.

Arikunto, S. (2014). Prosedur Penelitian Suatu Pendekatan Praktik. Jakarta : Rineka Cipta. Arikunto, Suharsimi 2014, 53(9).

Basler, H.-D. (1996). Health psychology - Biopsychosocial interactions, 2nd edition. Patient Education and Counseling, 29(2). https://doi.org/10.1016/0738-3991(96)00903-2

Fua, J. La, \& Gunawan, F. (2014). Pedoman Penulisan Karya Tulis Ilmiah. IAIN Kendari Press.

Jayasankara Reddy, K., Rajan Menon, K., \& Thattil, A. (2018). Academic Stress and its Sources Among University Students. Biomedical and Pharmacology Journal, 11(1), 531-537. https://doi.org/10.13005/bpj/1404.

Kumar, R. (2011). Stres and Coping Strategies among Nursing Students. Nursing and Midwifery Research Journal.

Pariat, M. L., Rynjah, M. A., Joplin, M., \& Kharjana, M. G. (2014). Stress Levels of College Students: Interrelationship between Stressors and Coping Strategies. IOSR Journal of Humanities and Social Science, 19(8), 40-45. https://doi.org/10.9790/0837-19834046.

Regehr, C., Glancy, D., \& Pitts, A. (2013). Interventions to reduce stress in university students: A review and meta-analysis. Journal of Affective Disorders, 148(1), 1-11. https://doi.org/10.1016/j.jad.2012.11.026

Rukmana, I. (2019). Coping Stress Penulis Skripsi (STudi Deskriptif pada Mahasiswa Angkatan 2012 Program Studi Bimbingan dan Konseling Universitas Snata Dharma Tahun Ajaran 2015/2016. UIN Syarif Hidayatullah.

Sipayung, N. (2016). Coping Stress Penulis Skripsi (STudi Deskriptif pada Mahasiswa Angkatan 2012 Program Studi Bimbingan dan Konseling Universitas Snata Dharma Tahun Ajaran 2015/2016. Universitar Sanata Dharma, Yogyakarta.

Ulrich-Lai, Y. M., \& Herman, J. P. (2009). Neural regulation of endocrine and autonomic stress responses. In Nature Reviews Neuroscience (Vol. 10, Issue 6). https://doi.org/10.1038/nrn2647. 
Wijayanti, N. (2013). Strategi Coping Menghadapi Stress Dalam Penyusunan Tugas AKhir Skripsi Pada Mahasiswa Program S1 Fakultas Ilmu Pendidikan. Universitas Negeri Yogyakarta.

Yulita, N., \& Susiono, D. E. (2020). Nilai Ekologi (Ecological Value) Hiu Hasil Tangkapan Nelayan di PPN Brondong Lamongan Jawa Timur. Biotropika: Journal of Tropical Biology, 8(1). https://doi.org/10.21776/ub.biotropika.2020.008.01.04. 